\title{
Delay in tuberculosis diagnosis and treatment in Amhara state, Ethiopia
}

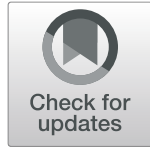

Melashu Balew Shiferaw ${ }^{1 *}$ and Amtatachew Moges Zegeye ${ }^{2}$

\begin{abstract}
Background: Delayed presentation is a major problem contributing to the high burden and transmission of tuberculosis (TB) in developing countries. The delay may be due to patient delay if the patient visits health-facility for diagnosis after the onset of symptoms of more than 3 weeks or health system delay if the patient is not diagnosed and treated at the time of the first visit. Ethiopia, where no more than two-thirds of TB cases are detected is no exception. Therefore, the aim of this study was to assess delay in diagnosis of tuberculosis among patients taking anti-TB treatment in North Shoa Zone, Ethiopia.

Methods: Institution based cross-sectional study was conducted from 01 to 30 December 2017. All TB patients who took their treatment in the health facilities of the seven selected districts of North Shoa Zone were included. Data was entered into EPI INFO version 3.5.1 statistical software and transferred into SPSS version 20.0 for further analysis. Bivariate and multivariate analysis was used to identify associated factors for delayed TB diagnosis.

Results: Out of 170 tuberculosis patients included, 162 patients were studied with a response rate of 95.3\%. The proportion of tuberculosis patients who had delayed diagnosis was 59.9\%. The mean time of health-seeking after developing the symptom of tuberculosis was 7.6 weeks. Tuberculosis patients with extra pulmonary site involvements were about four times more likely to be delayed in seeking health services (OR: 4.00, 95\% Cl: 1.77-9.03) as compared to patients with pulmonary TB. New patients were about three times more likely to come lately for TB diagnosis (OR: 2.94, 95\% Cl: 1.26-6.84) as compared to patients who had previous-history of treatment. Patients who had no information about TB before they started TB treatment were also around three times to be delayed (OR: 3.37, 95\% Cl: 1.43-8.00) as compared to those who had the information.
\end{abstract}

Conclusions: More than 50\% of TB patients reported in health-seeking relatively a longer time. Strengthening the health education activities for the community about tuberculosis and capacity building of the health care provider to increase suspicion of identifying tuberculosis and early diagnosis is crucial.

Keywords: Tuberculosis, Delay, Diagnosis, Health information

\section{Background}

Tuberculosis (TB) remains a major global health problem. It causes ill-health about 10 million people each year and is one of the top ten causes of death world-wide that kills three people within a minute [1-4]. For the past 5 years, it has been the leading cause of death from a single infectious agent. However, most people who develop TB disease can be cured with a timely diagnosis and correct treatment [4].

\footnotetext{
* Correspondence: bmelashu@gmail.com

${ }^{1}$ Amhara Public Health Institute, P.O.Box 447, Bahir Dar, Amhara, Ethiopia

Full list of author information is available at the end of the article
}

Ethiopia is still one among the 30 high burdens TB countries and The TB case detection rate is very low compared to the World Health Organization (WHO) target of detecting all infectious $\mathrm{TB}$ cases to reach annual decline of TB incidence by 4.5 to $5 \%$ [3-6].

If not totally missed, delayed identification and diagnosis of TB cases plays a vital role in the transmission of the disease in the community in most developing countries. The delay may be due to patient delay if the patient visits health-facility for diagnosis after the onset of symptoms of more than 3 weeks or health system delay if the patient is not diagnosed and treated at the time of the first visit. There is also delay from diagnosis to treatment initiation

(c) The Author(s). 2019 Open Access This article is distributed under the terms of the Creative Commons Attribution 4.0 International License (http://creativecommons.org/licenses/by/4.0/), which permits unrestricted use, distribution, and reproduction in any medium, provided you give appropriate credit to the original author(s) and the source, provide a link to the Creative Commons license, and indicate if changes were made. The Creative Commons Public Domain Dedication waiver (http://creativecommons.org/publicdomain/zero/1.0/) applies to the data made available in this article, unless otherwise stated. 
if treatment is not stated as soon as the diagnosis is done. Ethiopia, where not more than two-thirds of all cases are detected is not exceptional. Delay in the diagnosis of TB exists between recognition of symptoms and initiation of treatment [5] and late diagnosis of tuberculosis is likely to be associated with a worse prognosis owing to the presence of extensive disease and poor clinical condition [7-12]. According to $\mathrm{WHO}$, case fatality rate (CFR) reduction has been targeted to be $10 \%$ and lower. However, the CFR was 26\% in Ethiopia in 2017, which is very far from the target and more than half of the cases were due to delay in diagnosis and treatment [4].

Many people with active tuberculosis do not experience typical symptoms in the first stages of the disease and may not seek care early and tested for TB. To cure $\mathrm{TB}$ and cut disease transmission, patients should be diagnosed early and be placed on effective treatment soon after diagnosis [13].

In this regard, health facility-based studies have explored the duration of delay and factors related to health seeking among pulmonary patients. A study conducted in Ethiopia showed that there was health seeking behavior of TB suspects and no diagnostic capacity of a health facility in all forms of TB [14]. As these groups of cases may need well-organized health facility which may be more inaccessible, so these patients may long last without the diagnosis. In different localities and different geographical areas, information on diagnostic delay and contributing factors is thus important for the evaluation and improvement of TB control programs. Therefore, the aim of this study was to assess delay in TB diagnosis among patients taking TB treatment at the health facility level in North Shoa Zone, Ethiopia.

\section{Methods}

\section{Study design and period}

Institution based cross-sectional study design was conducted from 01 to 30 December 2017 to assess the delay in diagnosis of $\mathrm{TB}$ and associated factors for patients who were taking TB treatment at health centers in North Shoa zone, Ethiopia.

\section{Study site and population}

The study was conducted in seven districts of North Shoa Zone. North Shoa is one of the 11 Zones in the Amhara regional state. According to the central statistical agency estimate, the total population of the zone was $2,202,023$. The zone has 24 administrative districts, 9 hospitals, 95 health centers and 389 health posts. TB is a major public health problem in the zone. According to the zonal health office report, there were 1973 new and 126 previously treated TB patients in 2017 alone. Health posts refer TB suspects to health centers for diagnosis of $\mathrm{TB}$, whereas, hospitals and health centers provided TB diagnosis and treatment. As part of the TB prevention and control program, the health centers and hospitals should diagnose TB suspects and treat them immediately to reduce burden of $\mathrm{TB}$ as delayed diagnosis could lead to increased TB transmission especially in the era of MDR TB. Hence, this study was designed to assess whether there was a delay or not in the setting and share the information to take corrective actions for the problem of TB burden in the zone. Patients who took anti-TB treatment in all government health facilities in the sampled districts of North Shoa zone was the study population.

\section{Sample size}

The sample size was calculated using a single population proportion formula based on the following assumptions $\left(\mathrm{N}=\check{\mathrm{Z}}_{1 / 2} \mathrm{P} 1(\mathrm{P} 1-\mathrm{Q} 2) / \mathrm{W}^{2}\right)$ :

Proportion of delay in seeking health care after the onset of symptoms of TB was taken $89.9 \%$ (study from Bale zone southeast Ethiopia [14]), significant level at $\alpha=0.05$, at $95 \%$ confidence interval, margin of error was 5 and $10 \%$ non-response rate, the minimum sample size calculated was $143 \mathrm{~TB}$ patients. But to increase the sample size for higher precision in estimate, all TB patients who were taking TB treatment in all health facilities of selected districts at the time of data collection were included in the study regardless of age and sex. Only one TB patient who was unable to respond due to serious health conditions was excluded from the study.

\section{Sampling procedure}

There were a total of 24 districts in the north Shoa zone. About $30 \%$ of the total districts $(30 \%$ of $24=7.2 \approx 7$ ) were selected based on their cluster grouped using geographical proximity / remote or near to the capital of the zone/ and climate of the districts found in the zone (hot or cold areas) in order to represent the whole part of the North Shoa zone. Even though the sample size calculated was 143, all the patients who took anti-TB treatment in the government health facilities of the seven selected districts were included in the study at the time of data collection to have higher precision in estimate by increasing the sample size. Finally, a total of 162 patients under TB treatment in the seven districts were included consecutively (Fig. 1) when they came for collection of drugs.

\section{Operational definition \\ Patient delay}

Is defined as the period between the onset of the illness and patient first attendance of health care facility because of this illness. The patient was said delayed if he/she visited health-facility after onset of symptoms for more than 3 weeks ( 2 week entry point for presumptive Tb case and 1 week period to seek health care) [15]. 


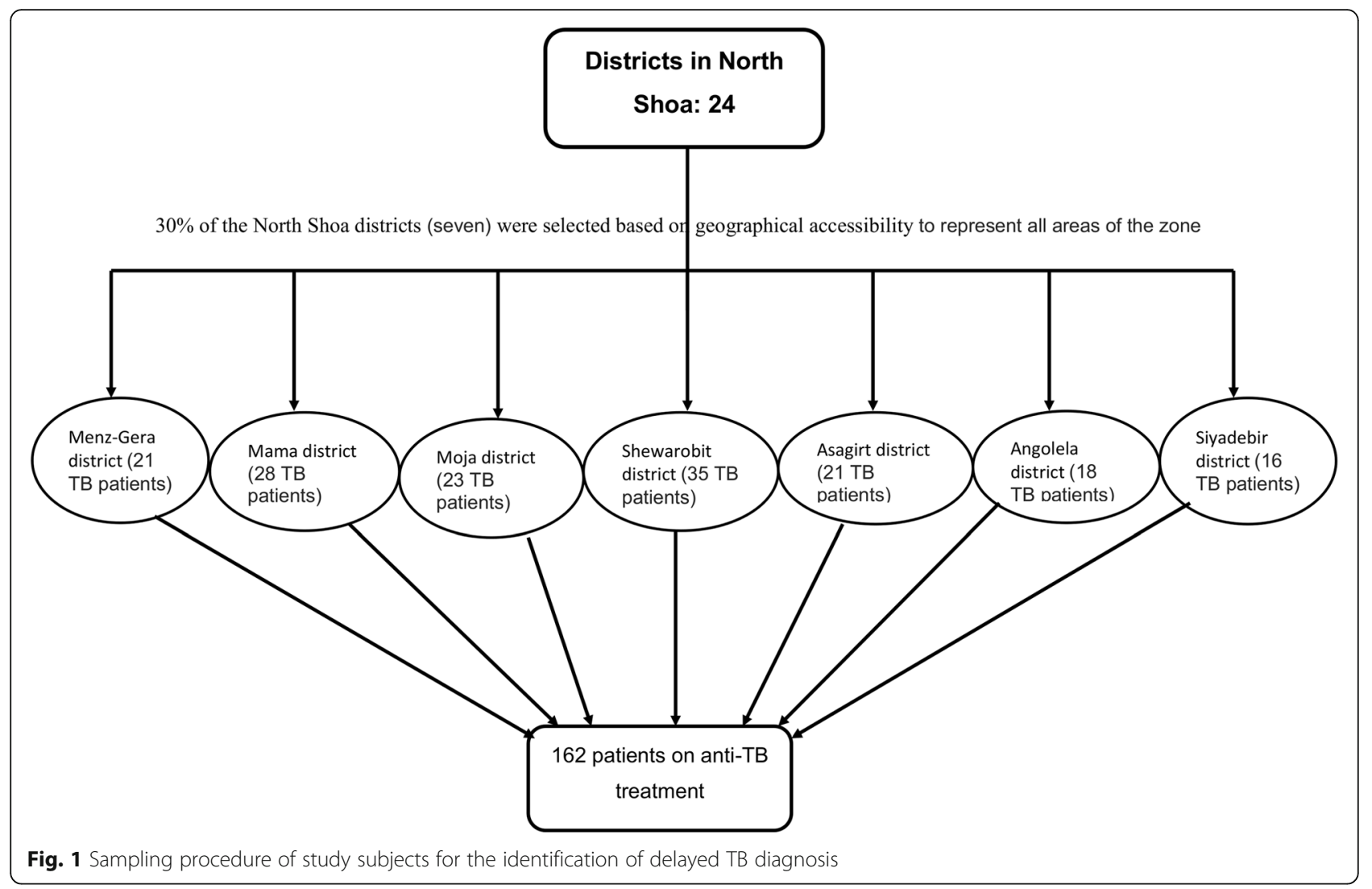

\section{Health system delay}

Is the period between patient's first attendance of health care facility with symptoms of TB and the diagnosis of Tuberculosis. The patient was said delayed if TB is not diagnosed and treated at the time of first visit [15].

The date of onset for the main symptoms was taken as the date of onset for the illness. For PTB patients, cough was taken as the main symptom whereas for EPTB patients, either localizing symptoms like swelling for TB lymphadenitis, chest pain for TB pleurisy or constitutional symptoms (fever, night sweats, weight loss, and loss of appetite) were taken as the onset of the illness whichever came first [15].

\section{Data collection procedure}

Data collection tool was first prepared in English and then translated to Amharic (local language). The second version of the tool was retranslated into the original one by language experts and investigators to check its consistency. The edited final version of the questionnaire was used to collect data from study subjects and from parents/guardians for children.

Trained district health office TB officers, one for each district, collected the data. Interview technique was used to collect data with structured and pre-tested questionnaire containing socio-demographic and treatment profile of TB patients. Data quality control pretest was done at Ataye health center. The health center that was not included in the study. The questionnaire was checked for consistency and completeness before conducting real data collection (see Additional file 1). Training was given for data collectors and supervisors about research objectives, data collection tools, procedures and interview techniques for 1 day. The data were collected by interviewing the study participants. However, data from children were collected using interview of the parents/guardians. The investigators, together with five supervisors supervised the data collection and checked completeness of the entire returned questionnaires daily.

\section{Data processing and analysis}

The returned data were entered into EPI info version 3.5.1 and transferred to Statistical Package for Social Science (SPSS) version 20.0 software for analysis. Descriptive and summary statistics were calculated. The patient was said delayed if he/she visited health facility for diagnosis after onset of symptoms more than 3 weeks after the onset of symptoms. Health system delay was considered if the patient was not diagnosed at the time of first-visit. Bivariate and multivariate logistic regression was used to identify associated variables. The multivariate logistic regression was adjusted using backward LR method. 
Variable having P- value up to 0.2 in bivariate analyses was entered into multivariate model. Variables with $P$-value $<0.05$ in the multivariate analysis was considered as significantly associated with delay in TB diagnosis.

\section{Ethical considerations}

Ethical clearance was assured prior to data collection from the Amhara Public Health institute Ethical Review. Permission was obtained first from North Shoal Health Department, then from the administrators of all health institutions. Each study participant was informed about the purpose, methods of collection, benefits and risk of the study by the data collector. Written informed consent was obtained from each participant. Regarding children the consent was found from their parents/ guardians. They were informed that they had the right to refuse or withdraw from the interview and it would not have any effect on the services they would have.

\section{Results}

Socio-demographic characteristics of study participants

Out of 170 tuberculosis patients included in this study, 162 (95.3\%) responded to participate in the study. The mean age of the respondent was 33.60 ( \pm 1.47 years). Ninety-two $(56.8 \%)$ respondent were male and $51.2 \%$ of the respondents were from rural area. Majority of the respondents (89.5\%) were orthodox Christian religion followers. Out of the total participants, 72 (44.2\%) were married and 60 (37\%) could not read and write (Table 1).

\section{Prevalence of delay and other variables of tuberculosis patients}

Table 2 describes the prevalence of delay and other related parameters of tuberculosis patients in the settings. The proportion of tuberculosis patients who had early health seeking (within 21 days of onset of the symptom) was only $40.1 \%$. The rest $59.9 \%$ of patients visited lately. Mean time of health seeking after developing the symptom of tuberculosis was 7.6 weeks ( \pm 1.22 weeks).

While the range of coming to the health-facility after developing the symptom was early as 1 week to 103 weeks. On the other hand, the mean of the second delay (after a patient went to the health facility to start TB treatment) was 33.3 days and ranges as early as 1 week to 51 weeks. Until the disease diagnosed, the patients had repeatedly come to the health-facility on average 3 $( \pm 1.9)$ times.

\section{Factors associated with delay in health seeking of tuberculosis patients}

Result from multivariate analysis showed that clients with pulmonary tuberculosis, who had got information
Table 1 Characteristics of tuberculosis patients in seven districts of North Shoa zone, Ethiopia, December 2017

\begin{tabular}{|c|c|c|}
\hline Variable & Number & Percent (\%) \\
\hline \multicolumn{3}{|l|}{ Sex } \\
\hline Male & 92 & 56.8 \\
\hline Female & 70 & 43.2 \\
\hline \multicolumn{3}{|c|}{ Age in years } \\
\hline $1-10$ & 5 & 3.1 \\
\hline $11-20$ & 29 & 17.9 \\
\hline $21-29$ & 49 & 30.2 \\
\hline 30-39 & 32 & 19.8 \\
\hline $40-50$ & 29 & 17.9 \\
\hline$>50$ & 18 & 11.1 \\
\hline \multicolumn{3}{|c|}{ Marital status } \\
\hline Married & 72 & 44.4 \\
\hline Not married & 65 & 40.1 \\
\hline Divorced & 12 & 7.4 \\
\hline Widowed & 13 & 8 \\
\hline \multicolumn{3}{|c|}{ Resident } \\
\hline Rural & 83 & 51.2 \\
\hline Urban & 79 & 48.8 \\
\hline \multicolumn{3}{|c|}{ Religion } \\
\hline Orthodox & 145 & 89.5 \\
\hline Muslim & 16 & 9.9 \\
\hline Protestant & 1 & 0.6 \\
\hline \multicolumn{3}{|c|}{ Educational status } \\
\hline Cannot read and write & 60 & 37 \\
\hline Can read and write & 56 & 34.6 \\
\hline Primary & 34 & 21 \\
\hline Secondary & 12 & 7.4 \\
\hline \multicolumn{3}{|c|}{ Number of Family } \\
\hline $0-2$ & 39 & 24.1 \\
\hline $3-6$ & 111 & 68.5 \\
\hline $7-9$ & 12 & 7.4 \\
\hline \multicolumn{3}{|c|}{ Jobs of respondent } \\
\hline Government employee & 17 & 10.4 \\
\hline Self employee & 44 & 27.1 \\
\hline Housewife & 2 & 1.2 \\
\hline Farmer & 74 & 45.6 \\
\hline Student & 16 & 9.9 \\
\hline Other & 9 & 5.8 \\
\hline \multicolumn{3}{|c|}{ Distance travel } \\
\hline $0-5 \mathrm{~km}$ & 91 & 56.2 \\
\hline Greater than $5 \mathrm{~km}$ & 71 & 43.8 \\
\hline
\end{tabular}


Table 2 Care seeking and investigations among tuberculosis patients in seven districts of North Shoa zone, Ethiopia, December 2017

\begin{tabular}{lll}
\hline Variable & Number & Percen \\
\hline $\begin{array}{l}\text { How many times you go to health } \\
\text { facility before you disease has been } \\
\text { diagnosed? }\end{array}$ & & \\
1 & 30 & 18.5 \\
2 & 58 & 35.8 \\
3 & 28 & 17.3 \\
4 & 13 & 8.1 \\
5 & 17 & 10.5 \\
6 & 5 & 3.1 \\
7 & 5 & 3.1 \\
8 & 4 & 2.4 \\
12 & 2 & 1.2
\end{tabular}

Delayed health seeking

$\begin{array}{lcc}\text { Diagnosed at first visit } & 65 & 40.1 \\ \text { Not diagnosed at first visit } & 97 & 59.9 \\ & & 79 \\ \text { Major reasons for patient delay for more that 21 days } & \\ \text { Symptom disappear by itself } & 76 & 10 \\ \text { Financial constrain } & 10 & 4 \\ \text { Used herbal medicine } & 4 & 7 \\ \text { Being HF distant } & 7 & \end{array}$

\section{Category of TB}

New

previously treated

22

The perception of cause of TB by the patients

$\begin{array}{lll}\text { Due to draft } & 78 & 48.2 \\ \text { Bacterial infection } & 59 & 36.4 \\ \text { Dust particle } & 14 & 8.6 \\ \text { Others } & 11 & 6.8\end{array}$

Where do you go first when you develop sign of TB

$\begin{array}{lll}\text { Health post } & 45 & 27.7 \\ \text { Hospital } & 59 & 36.4 \\ \text { Private HF } & 44 & 27.2 \\ \text { Holly water } & 9 & 5.6 \\ \text { Other } & 5 & 3.1\end{array}$

Asked about TB at first visit

$\begin{array}{lll}\text { yes } & 92 & 56.8 \\ \text { No } & 70 & 43.2\end{array}$

Type of TB

Pulmonary

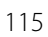

Table 2 Care seeking and investigations among tuberculosis patients in seven districts of North Shoa zone, Ethiopia, December 2017 (Continued)

\begin{tabular}{lll}
\hline Variable & Number & Percent \\
\hline Extra pulmonary & 47 & 29 \\
& Give Sputum Sample at first visit & \\
Yes & 86 & 53.1 \\
No & 76 & 46.9 \\
& & \\
& Previous contact history \\
Yes & 43 & 26.5 \\
No & 119 & 73.5 \\
& & \\
The patient by itself & Who initiated you to Health facility & \\
Spouse of the patients & 75 & 46.3 \\
Health extension worker & 22 & 13.6 \\
My family & 10 & 6.1 \\
Other relative & 19 & 11.7 \\
HAD leaders & 24 & 14.9 \\
Other & 6 & 3.7 \\
\hline
\end{tabular}

about tuberculosis and those with the history of previous TB treatment were significantly and independently associated with delay in health seeking. Sex of respondent, age, educational status, residence, marital status, type of health-facility first attended, history of previous contact, distance travel and religion of the respondent were not significantly associated with delay in health seeking of tuberculosis.

Accordingly, tuberculosis patients with extra pulmonary site involvements were about four times more likely to delay in seeking health service (OR: 4.00, 95\% CI: 1.77-9.03) as compared with patients with only pulmonary site involvement. New patients were about three times more likely to come lately for TB diagnosis (OR: 2.94, 95\% CI: 1.26-6.84) as compared with those who had previous-history of treatment. Tuberculosis patients who had no information about tuberculosis in before they started this treatment were also around three times more likely to delay in health service seeking for tuberculosis treatment (OR: 3.37, 95\% CI: $1.43-8.00$ ) as compared with those who had any information about tuberculosis before they started the treatment (Table 3).

\section{Discussion}

Delay in health-seeking of tuberculosis patients have a number of public health impacts in the patients as well as in the community and country as a whole like 
Table 3 Determinants of delay in diagnosis of tuberculosis in seven districts North Shoa zone, Ethiopia, December 2017

\begin{tabular}{|c|c|c|c|c|}
\hline \multirow[t]{2}{*}{ Variable } & \multicolumn{2}{|c|}{ Delay in health seeking } & \multirow{2}{*}{$\begin{array}{l}\text { Crude OR } \\
(95 \% \mathrm{Cl})\end{array}$} & \multirow{2}{*}{$\begin{array}{l}\text { Adjusted OR } \\
(95 \% \mathrm{Cl})\end{array}$} \\
\hline & Yes n (\%) & No n (\%) & & \\
\hline \multicolumn{5}{|l|}{ Type of Tb (in site) } \\
\hline Pulmonary & $59(36.4)$ & $56(34.6)$ & 1.00 & 1,00 \\
\hline Extra pulmonary & $38(23.5)$ & $9(5.6)$ & $4.0(1.77-9.03)$ & $3.41(1.46-7.95)$ \\
\hline \multicolumn{5}{|c|}{ Treatment history of patients } \\
\hline New & $91(56.2)$ & $49(30.2)$ & $4.9(1.8-13.4)$ & $2.94(1.26-6.84)$ \\
\hline Previously treated & $6(3.7)$ & $16(9.6)$ & 1.00 & 1.00 \\
\hline \multicolumn{5}{|c|}{ Heard information about TB } \\
\hline Yes & $63(38.9)$ & $56(34.6)$ & 1.00 & 1.00 \\
\hline No & $34(21)$ & $9(5.6)$ & $3.36(1.48-7.61)$ & $3.37(1.43-8.00)$ \\
\hline
\end{tabular}

OR was adjusted using multivariate logistic regression backward LR method

unfavorable treatment outcome, increase transmission of the disease in the community and economic crisis in the country. An important preventable period of infectiousness in the community may be increased due to the habit of life priority and low awareness as well as once they came to the health-facility very low suspicion and identification of presumptive TB case in the health service provision $[3,4]$.

The delay in TB diagnosis found in this study (59.9\%) is higher than the study done in east Wollega (42.3\%), Ethiopia [9]. It may be due to variation in study subjects, where only pulmonary TB cases were included in Wollega. When we compare it with the country goal of ending TB strategy, it is far from the target because more than half of TB patients were delayed that could spread TB in the community. Out of those who delayed for health seeking, 79\% of them believe that they will get relief by itself. This may indicate the low community awareness and miss conception about the disease provided that any presumptive $\mathrm{TB}$ case has to undergo proper evaluation for TB. Moreover, $48 \%$ of study participants believed that the case of TB is due to draft. This may indicate that the general lack of awareness about the source of TB infection so that they were not able to prevent the disease.

Beyond the delay in health seeking at community level, only $56 \%$ of TB patients were asked about symptoms of $\mathrm{TB}$ at first health facility visit and $53.4 \%$ gave sputum samples for AFB diagnosis. This indicates that there were miss opportunities in addressing the TB patients and regarding performing sputum AFB, it may be due to the low accessibility of the service as only $60 \%$ of the health facilities had the service in north Shoa zone districts. This problem was also seen in a Taiwan study that showed increased health system delay to diagnose and treat tuberculosis between 2003 and 2008 [16]. On the other hand, $27.8 \%$ of patients had first-visit at health post, which is higher compared to studies done in
Wollega (17\%) and Bale regions (14.8\%) [9, 14] even though it did not show significant difference.

The result of this study showed that the site of TB disease is a factor for delay in health seeking. Accordingly, TB patients with extra pulmonary site involvements were about four times more likely to delay in seeking health service when developing signs and symptoms of TB as compared with patients with only pulmonary site involvement. This is similar with a study done in Bale [14] where extra pulmonary patients were delayed than that of pulmonary patients. This may be due to the fact that the signs and symptoms of extra pulmonary TB patients may be more constitutional and organ-specific so that it may be difficult to recognize early by the community as pulmonary cases. Although EPTB patients may not be more infectious to the community, they may suffer long-term disease, and disability.

This study found that new TB patients were about three times more likely to come lately for TB diagnosis as compared with those who had previous history of anti-tuberculosis treatment. It is similar with a study done in the rural part of Ethiopia [17]. This may indicate that once patients develop the disease, they will get information about the disease and for the next time when they develop sign and symptoms, they will seek treatment early.

Tuberculosis patients who did not have information about TB were more likely to delay in health-seeking. Accordingly, tuberculosis patients who had no information about tuberculosis in different way before they started this treatment were also around three times more likely to delay in health service seeking for tuberculosis as compared with those who have any information about tuberculosis. This finding is similar with a study conducted about knowledge and health seeking behavior of TB patients in south-west Ethiopia [17]. This may indicate that there were no clear information and awareness creation activities in the community. 
Hence, the role of health facilities, districts and the zone health department is tremendous and needs to plan, coordinate, and evaluate TB control and prevention efforts. As part of the prevention and control program early TB diagnosis is one of the strategies in order to reduce the spread of TB in the region. In addition, district health office and the zonal health departments should focus and provide oversight the clinical and diagnostic services for patients with $\mathrm{TB}$ and their contacts, training and education, and monitoring and evaluation to solve the problem further.

As limitation, the study participants were selected after the $\mathrm{TB}$ diagnosis that may lead to a recall bias. In addition, underlying diseases of the patients' status such as diabetes mellitus and HIV status were not considered during the time of data collection.

\section{Conclusions}

This study showed that almost $60 \%$ of TB patients were reported health seeking relatively in longer time. There was also delayed diagnosis at health facility level after the patients had initiated health seeking despite different effort made to increase the index of suspicion and capacity of health care worker and health facility to end the TB epidemic. Lack of information about tuberculosis, previous treatment history, and site of the disease were factors for delayed diagnosis. Strengthening community health education activities about tuberculosis and capacity building of the health care providers are important interventions to increase suspicion of identifying tuberculosis and importance of early diagnosis.

\section{Additional file}

Additional file 1: Interview guide questionnaire. (DOCX $18 \mathrm{~kb}$ )

\section{Abbreviations}

EPTB: Extra pulmonary tuberculosis; PTB: Pulmonary tuberculosis; TB: Tuberculosis; WHO: World Health Organization

\section{Acknowledgements}

We would like to thank to colleagues, data collectors and supervisor who give us constructive ideas and comments. We also thank study participants for their commitment to share the information. Without their cooperation and permission, this study would not be realized.

\section{Funding}

The authors do not receive specific support or funding to report.

Availability of data and materials

All data supporting these findings is contained within the manuscript.

\section{Authors' contributions}

AMZ made substantial contribution for conception, design and collection of the data. Both AMZ and MBS made substantial contribution to analysis and interpretation of data, involved in drafting the manuscript. MBS has contributed to revising the manuscript critically for important intellectual content. Both authors have given final approval of the version to be published.

\section{Ethics approval and consent to participate}

Ethical clearance was assured prior to data collection from the Amhara Public Health institute Ethical Review. Permission was obtained first from North Shoal Health Department, then from the administrators of all health institutions. Each study participants was informed about the purpose, methods of collection, anticipated benefit and risk of study by the data collector. Written informed consent was obtained from each participant. Regarding children the consent was found from their parents/guardians. They were informed that they had the right to refuse or withdraw from interview and it would not have any effect on the services they would have.

\section{Consent for publication}

Not applicable. This manuscript does not contain any individual persons' data.

\section{Competing interests}

The authors declare that they have no competing interests.

\section{Publisher's Note}

Springer Nature remains neutral with regard to jurisdictional claims in published maps and institutional affiliations.

\section{Author details}

${ }^{1}$ Amhara Public Health Institute, P.O.Box 447, Bahir Dar, Amhara, Ethiopia. ${ }^{2}$ North Shoa Zone Health Department Tuberculosis, HIV and Leprosy program coordinator, Debre Birhan, Shoa, Ethiopia.

Received: 17 September 2018 Accepted: 2 April 2019

Published online: 16 April 2019

\section{References}

1. World Health Organization. Global tuberculosis report. Geneva: WHO press; 2014

2. Jagger A, Reiter-karam S, Hamada Y, Getahun H. National policies on the management of latent tuberculosis infection: review of 98 countries. Bull World Health Organ. 2018;96:173-184F.

3. World Health Organization. Global tuberculosis report. Geneva: WHO press; 2015

4. World Health Organization. Global tuberculosis report. Geneva: WHO press; 2017

5. World Health Organization. Global tuberculosis report. Geneva: WHO press; 2013

6. Mahendradhata Y, Syahrizal BM, Utarini A. Delayed treatment of tuberculosis patients in rural areas of Yogyakarta province, Indonesia. BMC Public Health. 2008;8:393.

7. Mesfin MM, Newell JN, Walley JD, Gessessew A, Madeley RJ. Delayed consultation among pulmonary tuberculosis patients: a cross sectional study of 10 DOTS districts of Ethiopia. BMC Public Health. 2009;9:53.

8. Uys PW, Warren RM, van Helden PD. A threshold value for the time delay to TB diagnosis. PLoS One. 2007;2(8):e757.

9. Wondimu T, W/Michael K, Kassahun W, Getachew S. Delay in initiating tuberculosis treatment and factors associated among pulmonary tuberculosis patients in East Wollega, Western Ethiopia. Ethiop J Health Dev. 2007:21(2):149-56.

10. Okeibunor JC, Onyeneho NG, Chukwu JN, Post E. Where do tuberculosis patients go for treatment before reporting to DOTS clinics in southern Nigeria? Tanzan Health Res Bull. 2007;9(2):94-101.

11. Huong NT, Vree M, Duong BD, Khanh VT, Loan VT, Co NV, Borgdorff MW, Cobelens FG. Delays in the diagnosis and treatment of tuberculosis patients in Vietnam: a cross-sectional study. BMC Public Health. 2007;7:110.

12. Storla DG, Yimer S, Bjune GA. A systematic review of delay in the diagnosis and treatment of tuberculosis. BMC Public Health. 2008:8:15.

13. Stop TB Partnership, UNOPS. Global plan to end TB 2016-2020. Geneva: WHO press; 2015.

14. Hussen A, Biadgilign S, Tessema F, Mohammed S, Deribe K, Deribew A. Treatment delay among pulmonary tuberculosis patients in pastoralist communities in bale zone, Southeast Ethiopia. BMC Res Notes. 2012:5:320.

15. Federal Ministry of Health. Guidelines for clinical and programmatic management of TB, leprosy and TB/HIV in Ethiopia. Addis Ababa: Falcon printing PLC; 2013. 
16. Chen C, Chiang C, Pan S, Wang J, Lin H. Health system delay among patients with tuberculosis in Taiwan: 2003-2010. BMC Infect Dis. 2015;15:491.

17. Abebe G, Deribew A, Apers L, Woldemichael K, Shiffa J, Tesfaye M, Abdissa

A, Deribie F, et al. Knowledge, health seeking behavior and perceived stigma towards tuberculosis among tuberculosis suspects in a rural community in Southwest Ethiopia. PLoS One. 2010;5(10):e13339.

Ready to submit your research? Choose BMC and benefit from:

- fast, convenient online submission

- thorough peer review by experienced researchers in your field

- rapid publication on acceptance

- support for research data, including large and complex data types

- gold Open Access which fosters wider collaboration and increased citations

- maximum visibility for your research: over $100 \mathrm{M}$ website views per year

At BMC, research is always in progress.

Learn more biomedcentral.com/submissions 